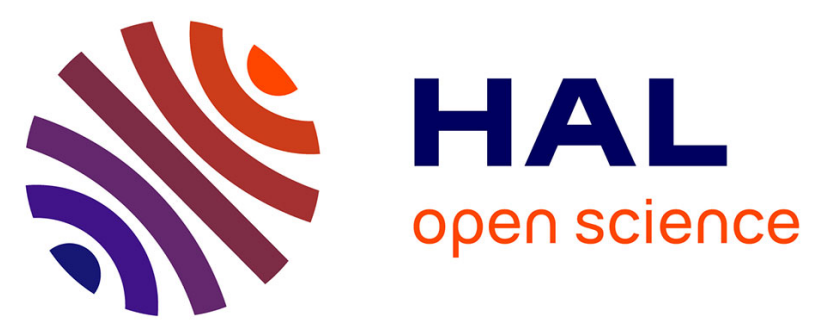

\title{
Identification of plant micro-reserves using conservation units and population vulnerability: The case of an endangered endemic Snowflake (Acis nicaeensis) in the Mediterranean Basin hotspot
}

Frédéric Médail, Katia Diadema, Marine Pouget, Alex Baumel

\section{To cite this version:}

Frédéric Médail, Katia Diadema, Marine Pouget, Alex Baumel. Identification of plant micro-reserves using conservation units and population vulnerability: The case of an endangered endemic Snowflake (Acis nicaeensis) in the Mediterranean Basin hotspot. Journal for Nature Conservation, 2021, 61, pp.125980. 10.1016/j.jnc.2021.125980 . hal-03159122

\section{HAL Id: hal-03159122 \\ https://hal-amu.archives-ouvertes.fr/hal-03159122}

Submitted on 27 Apr 2021

HAL is a multi-disciplinary open access archive for the deposit and dissemination of scientific research documents, whether they are published or not. The documents may come from teaching and research institutions in France or abroad, or from public or private research centers.
L'archive ouverte pluridisciplinaire HAL, est destinée au dépôt et à la diffusion de documents scientifiques de niveau recherche, publiés ou non, émanant des établissements d'enseignement et de recherche français ou étrangers, des laboratoires publics ou privés.

\section{(ㅇ)(1) $\$$}

Distributed under a Creative Commons Attribution - NonCommercial - NoDerivatives 44.0 


\title{
Identification of plant micro-reserves using conservation units and population vulnerability: The case of an endangered endemic Snowflake (Acis nicaeensis) in the Mediterranean Basin hotspot
}

\author{
Frédéric Médail $^{\mathrm{a}, *}$, Katia Diadema ${ }^{\mathrm{b}}$, Marine Pouget ${ }^{\mathrm{a}}$, Alex Baumel $^{\mathrm{a}}$ \\ ${ }^{a}$ Institut Méditerranéen de Biodiversité et d'Ecologie marine et continentale (IMBE), Aix Marseille Univ, CNRS, IRD, Avignon Univ. Technopôle de l'Arbois-Méditerranée, \\ BP 80, 13545 Aix-en-Provence Cedex 4, France \\ ${ }^{\mathrm{b}}$ Conservatoire Botanique National Méditerranéen de Porquerolles (CBNMed), 34 Avenue Gambetta, 83400 Hyères, France
}

A R T I C L E I N F O

Keywords:

Biodiversity

Conservation priorities

Evolutionary originality

Maritime Alps

Narrow endemic plant

Plant micro-reserve

Urbanization

\begin{abstract}
A B S T R A C T
Erosion of natural habitats due to urban sprawl constitutes a major threat to biodiversity. The development of the Plant Micro-Reserve (PMR) is an efficient concept for the in situ conservation of rare plants with narrow ecological niche and threatened by human impacts. We provide a framework for initiating site selection of PMRs, including evolutionary and ecological uniqueness. The proposed cross-analysis is based on (i) the estimate of population vulnerability, (ii) the contribution of each population to the evolutionary originality of the species by designating conservation units, and (iii) the gap analysis of the current protection status of the populations. As a case study, we apply this framework to the Nice Snowflake Acis nicaeensis, a narrow Mediterranean endemic plant of the French-Italian Riviera which, being caught in the turmoil of urban sprawl, is threatened by tremendous anthropogenic pressures. On the basis of historical data (past land-use and herbarium data) we show that over the last 150 years, the impact of urbanization has been severe for $70 \%$ of the populations and has caused the disappearance of at least 11 of them, i.e. $20 \%$ of the known populations. Similar levels of urban sprawl are observed between the most vulnerable and already extinct populations. In this context of biodiversity decline, our cross-analysis highlights that two of the five conservation units call for a rapid setting up of PMRs because of their high originality and their great risk of extinction: one unit including the populations of the Principality of Monaco and one unit that includes the populations of Nice and its surroundings. This study demonstrates the importance of integrating population vulnerability and conservation units. In a context of huge urbanization our approach makes a clear case for the design of PMRs.
\end{abstract}

\section{Introduction}

In the context of the severe biodiversity crisis of the Anthropocene, urbanization and habitat destruction or degradation of natural ecosystems are the primary drivers of plant extinctions worldwide, notably in biodiversity hotspots where they represent $39 \%$ of the deleterious drivers vs $25 \%$ for the coldspots (Le Roux et al., 2019). Urban expansion is occurring at an unprecedented scale, and today more than $50 \%$ of the global human population live in urban environments (United Nations, 2018). The urban ecological footprint extends beyond city boundaries and drives severe environmental and biological changes (e.g. Grimm et al., 2008; Hahs et al., 2009; Wenzel et al., 2020). Indeed, urban areas threaten ecosystems as a result of direct habitat conversion (McKinney,
2002) and through various indirect effects, e.g. land-use changes, fragmentation by linear infrastructures such as roads, waste generation disturbances associated with recreational activities and diverse pollution (e.g. DeFries et al., 2007; Mcdonald et al., 2008). Urbanization changes the biological integrity of habitats and the nature of food webs between species. High levels of urban densification (above $50 \%$ ) has largely led to pollinator declines and loss of pollination services (Wenzel et al., 2020). Another impact is related to the frequent invasion by exotic species in natural areas adjacent to urbanized sectors, since habitat invasiveness is associated with disturbed landscapes (With, 2002).

As important biodiversity hotspots, Mediterranean-type ecosystems are particularly threatened by the increase of population density and urban areas (García-Nieto et al., 2018; Egidi et al., 2020; UNEP/MAP \&

\footnotetext{
* Corresponding author.

E-mail addresses: frederic.medail@imbe.fr (F. Médail), k.diadema@cbnmed.fr (K. Diadema), alex.baumel@imbe.fr (A. Baumel).
} 
Plan Bleu, 2020). In the Mediterranean region, the severe distortion between the loss of natural environments and their protection (Hoekstra et al., 2005; Cuttelod et al., 2008; Doxa et al., 2017) implies a need to develop integrative policies of preservation through the strengthening of the network of protected areas (Underwood et al., 2009). But the high biodiversity, environmental heterogeneity and vulnerability of the Mediterranean Basin hotspot (Médail \& Quézel, 1997; Blondel \& Médail, 2009), combined with various political or administrative organizational schemes, preclude large scale conservation efforts that are often ineffective. It is therefore often necessary to build a more local and smaller-scale approach to preserve rare species. Despite the importance of the urbanization phenomenon for the alteration of Mediterranean biodiversity and ecosystem service supply (García-Nieto et al., 2018), very few studies examine the consequences of these impacts and the possibilities of mitigating the induced effects on rare plants (e.g., Lhotte et al., 2014; Sulis et al., 2020; Abdel Samad et al., 2021).

An efficient tool for the in situ protection of the threatened Mediterranean plants was the development of the Plant Micro-Reserve (PMR) network, a concept that was successfully developed 30 years ago first in Spain and then in other European and Mediterranean countries (Laguna et al., 2004; Kadis et al., 2013). Although no fixed limit exists for the size of a PMR, this kind of small protected area is generally comprised between 0 and 100 ha. However, the definition of PMR remains quite empirical and based on the presence of one or more very rare and highly threatened plant species, mostly endemic, without clearly taking into account their evolutionary and functional components (Laguna \& Deltoro, 2013). These shortcomings represent crucial shortfalls for conservation policies (Hoban et al., 2020). They prevent the integration of the evolutionary history and the adaptive potential of the populations which are decisive for rare plant conservation in heterogeneous Mediterranean environments (Médail \& Baumel, 2018; Thompson, 2020). This could also preclude the efficient conservation of unique populations in terms of evolutionary and ecological originality, and therefore the preservation of the global evolutionary heritage of the species. To better define relevant PMRs for a focus species, we propose to include a more complete assessment of its evolutionary and ecological patterns. Our approach is based on a spatial comparison of conservation units and population vulnerability with regards to the current conservation network. When genetic evidence is not available to delineate conservation units (e.g. Baumel et al., 2020), environmental and floristic data can be used to account for ecological distinctiveness which is an important component of the adaptive potential at the species level (Crandall et al., 2000).

To assess the relevance of this new PMR approach, we chose to study a highly urbanized area: the coastal region of the Maritime and Ligurian Alps (i.e. the French-Italian Riviera), one of the then regional biodiversity hotspots of the Mediterranean region (Médail \& Quézel, 1997; Médail \& Diadema, 2006) which is severely threatened by urban sprawl (Vimal et al., 2012). Our case study is focused on a narrow endemic plant: the Nice Snowflake Acis nicaeensis, a species directly impacted by land-use changes such as urbanization and tourist resort development (Diadema et al., 2007a, b; Pouget et al., 2017). An ecological and genetic delineation was previously performed in order to identify the conservation units for this species (see Pouget et al., 2017). Historical records from herbaria tend to indicate a reduction of Snowflake populations Diadema et al., 2007b) but no detailed analysis has been carried out to quantify this process and the vulnerability of this rare species, and a global conservation program is missing.

The main objectives of this study are (i) to propose a better distinction of Plant Micro-reserves (PMRs) by spatially integrating population vulnerability and conservation units, ii) to apply this method for a better distinction of original, highly threatened and not yet protected populations of a narrow endemic plant located in a highly urbanized area, (iii) to examine the appropriateness of the use of the PMRs in these patchy and heterogeneous Mediterranean landscapes.

\section{Materials and methods}

\subsection{Study site and species}

The Nice Snowflake (Acis nicaeensis (Ardoino) Lledo, A.P.Davis \& M. B.Crespo, Amaryllidaceae) is a narrow endemic plant from the Maritime Alps, characterized by a patchy distribution on calcareous rocky grasslands. The distribution of $A$. nicaeensis covers approximately $420 \mathrm{~km}^{2}$, between the Pre-Alps of Grasse (col de Vence) to the West, and the only Italian population near the French-Italian border (Grimaldi, near Ventimiglia) to the East, including the five populations (two extinct) of the Principality of de Monaco (Fig. 1). The highest population density is found between Nice and Menton (Diadema, 2006; Pouget et al., 2017). This Snowflake is characterized by a large ecological amplitude and it occurs between 5 and $1000 \mathrm{~m}$ a.s.l., i.e. from the thermo-Mediterranean to the upper meso-Mediterranean vegetation levels (Diadema et al., 2007a, b).

The species has only several thousand individuals scattered to form a highly fragmented and heterogeneous distribution range. It is registered in the annexes II and IV of the European Habitats Directive, and is included in the IUCN Red list of threatened vascular plants as an endangered taxa (EN) both in France (UICN et al., 2018) and in Italy (Orsenigo et al., 2018). Several factors threaten this species, and during the XIXth and early XXth centuries some populations were severely damaged by massive sampling for herbarium collections (Diadema, 2006). Nowadays, the major threats are the huge development of urbanization along the coast of the Maritime Alps, the increase of the tourism activities and the impact of invasive plants (Diadema, 2006; Diadema et al., 2007b).

\subsection{Population structure and conservation units}

The data collection consists of 804 geolocated occurrence data of A. nicaeensis (http://flore.silene.eu), for a total of 53 populations (42 current and 11 extinct) whose delimitation is based on a geographical discontinuity of more than $500 \mathrm{~m}$ between two populations (Fig. 2). The area of each population was calculated as the size of a polygon representing the area of the population in two dimensions (elevation wasn't taken into account) using SIG software QGIS 3.10 (QGIS Development Team, 2020). Surface areas of populations vary between 4 and 170 ha and they were classified into three classes: small (I) = population area inferior to 20 ha; medium (II): population area between 20 and 50 ha; large (III) $=$ population area superior to 50 ha.

The assessment of historical localities was performed using the 195 specimens contained in diverse herbaria: Aix-en-Provence (AIX), Firenze (FI), Geneva (GE), Genova (G), Grenoble (GR), Lyon (LY), Marseille (MARS), Paris-MNHN (P), Montpellier (MPU), Nice (NICE) and Torino (TO). This made it possible to precisely locate 78 historical occurrences (see Diadema, 2006 for more detail). The disappearance of several historical localities was attested by visiting these areas several consecutive years.

The ecological and evolutionary divergences between the populations of Acis nicaeensis has allowed us to define five conservation units. Phylogeographical structure (three groups according to plastid haplotypes revealed) was considered as a proxy for evolutionary legacy, and ecological differentiation (three groups defined by multivariate analysis of habitat) was used as a proxy for ecological distinctiveness. Two populations were assigned to the same conservation unit if bearing the same haplotype and living in the same ecological group (see Pouget et al., 2017 for more details, and Fig. 2b). The shape of each conservation unit depends on the area and the actual geographic configuration of each population that composes it.

\subsection{Urbanization level and population vulnerability}

Urbanization level and urban sprawl were estimated per population of A. nicaeensis using two maps: (i) the "Carte d'État-Major" (EM) map, 


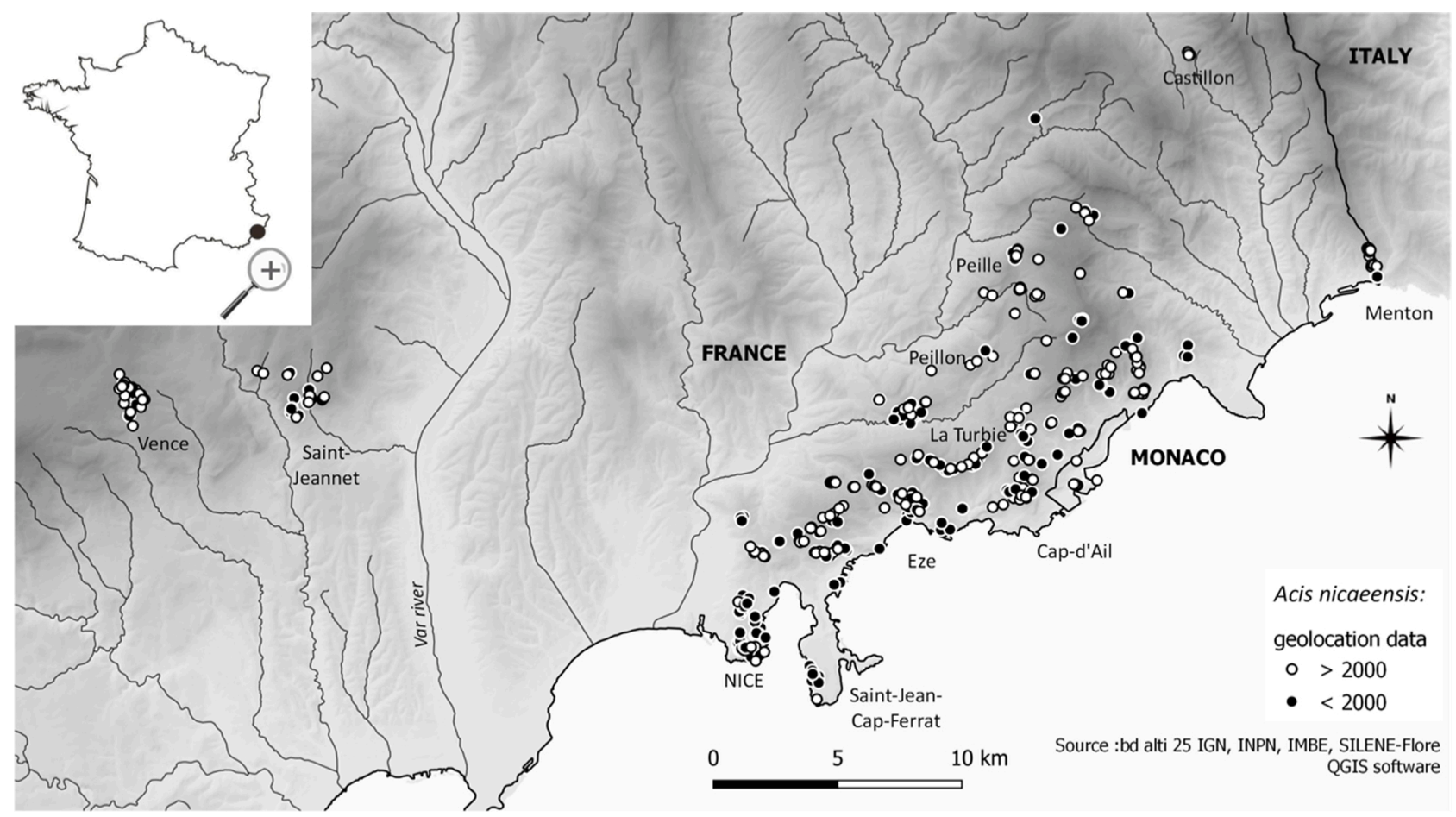

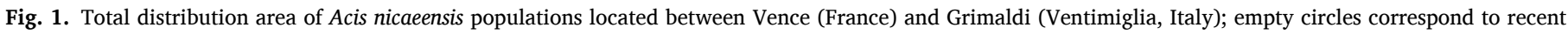
populations $(>2000)$ and full circles correspond to ancient populations $(<2000)$.

drawn in 1866 to estimate "past urbanization" (Fig. A1a) and (ii) the IGN (National Institute of Geography, France) map of 2006 to estimate "current urbanization" (Fig. A1b). The EM map is the oldest available with sufficient details to document and quantify roads or buildings, and the IGN map presents similar spatial features thus allowing the best diachronic comparison. The term "urbanization" included all the possible artificialization features such as buildings of all types, sport centers and fields, roads, staircases, parkings, water tanks etc.

A class value of urbanization was given for a $100 \times 100 \mathrm{~m}$ grid for each period. We used mesh to easily assess artificialization pooled in 5 classes: $0=$ no urbanization; $1=$ urbanization for less than $25 \%$ of surface; 2 = urbanization between 25 and $50 \%$ of surface; $3=$ urbanization between 50 and $75 \%$ of surface; 4 = urbanization for more than $75 \%$ of surface. The final urbanization percentage is the average of all mesh values present within an Acis' population polygon. The difference between the current urbanization and the past urbanization (IGN value minus - EM value) was used to estimate the urban sprawl rate. The value were converted in $\%$ to be more explicit (Fig. 2a). A permutation test based on absolute differences between medians was performed in $\mathrm{R}(\mathrm{R}$ core team, 2020) to evaluate if the level of urban sprawl of the extinct populations is significantly higher than the level of those extinct ( $R$ code available in supplementary material: Table A3).

To assess population vulnerability, we used a simple vulnerability index combining three classes of populations superficies (small, medium, large: see above) and four classes of urbanization. This vulnerability index was assigned to each population, including five classes (Table 1 ): $\mathrm{V} 0$ = populations of any surface area with no urbanization (I) or low urbanization (II) in large populations; V1 = populations with low urbanization (II) and small or medium populations; V2 and V3 = average (III) or high urbanization (IV) according to the surface area of the populations; V4 = small or medium and highly urbanized (IV) populations. A vulnerable population (classes V2, V3 and V4) will be even more vulnerable if the number of individuals is low. The high number of individuals per population ( $>500$ individuals) are found in less vulnerable populations (V0).

\subsection{Current protected area network}

The cartographic data of the protected areas where the Snowflake occurs were compiled both for France (Région Sud-Provence-Alpes-Côte d'Azur) and for Italy (Regione Liguria), as no protected area currently exists in the Principality of Monaco. It was necessary to standardize the various existing statuses of protected areas according to the IUCN classification (Dudley, 2008; Lefebvre \& Moncorps, 2010). Two types of protected area networks were considered, depending on the level of protection and the management implemented therein: (i) the global protection network which groups IUCN categories I to 4, i.e. protected areas exclusively dedicated to the conservation of biodiversity (e.g. core area of national park, national natural reserve, sites of the Conservatoire du littoral in France) or aimed at reconciling the conservation of nature and the sustainable use of resources (e.g. regional biological reserve, forest reserve); (ii) the European Natura 2000 network.

The geographic outlines of the two networks were obtained for France from the INPN (National Inventory of Natural Heritage: http ://inpn.mnhn.fr), the DREAL-PACA and the Conservatoire du littoral, while for Italy the data was provided by the Liguria region. The different protected areas of IUCN (levels I-IV) were merged (QGis 3.10 software: QGIS Development Team, 2020) to form a single cartographic layer. Degrees of spatial overlap between the general population distribution envelope of each Snowflake population and the related protected areas were calculated. Then, to find populations that should be included in Plant Micro-Reserves (PMRs) we looked for unprotected populations with high vulnerability and high conservation values. Thus for each population, we examined their spatial overlap with current protected areas, their conservation units already defined by Pouget et al. (2017) and their vulnerability (Table 1). This approach refers to the gap analysis methodology, performed for example in the conservation of threatened flora of some Mediterranean countries (Christodoulou et al., 2018; Laguna et al., 2016). 

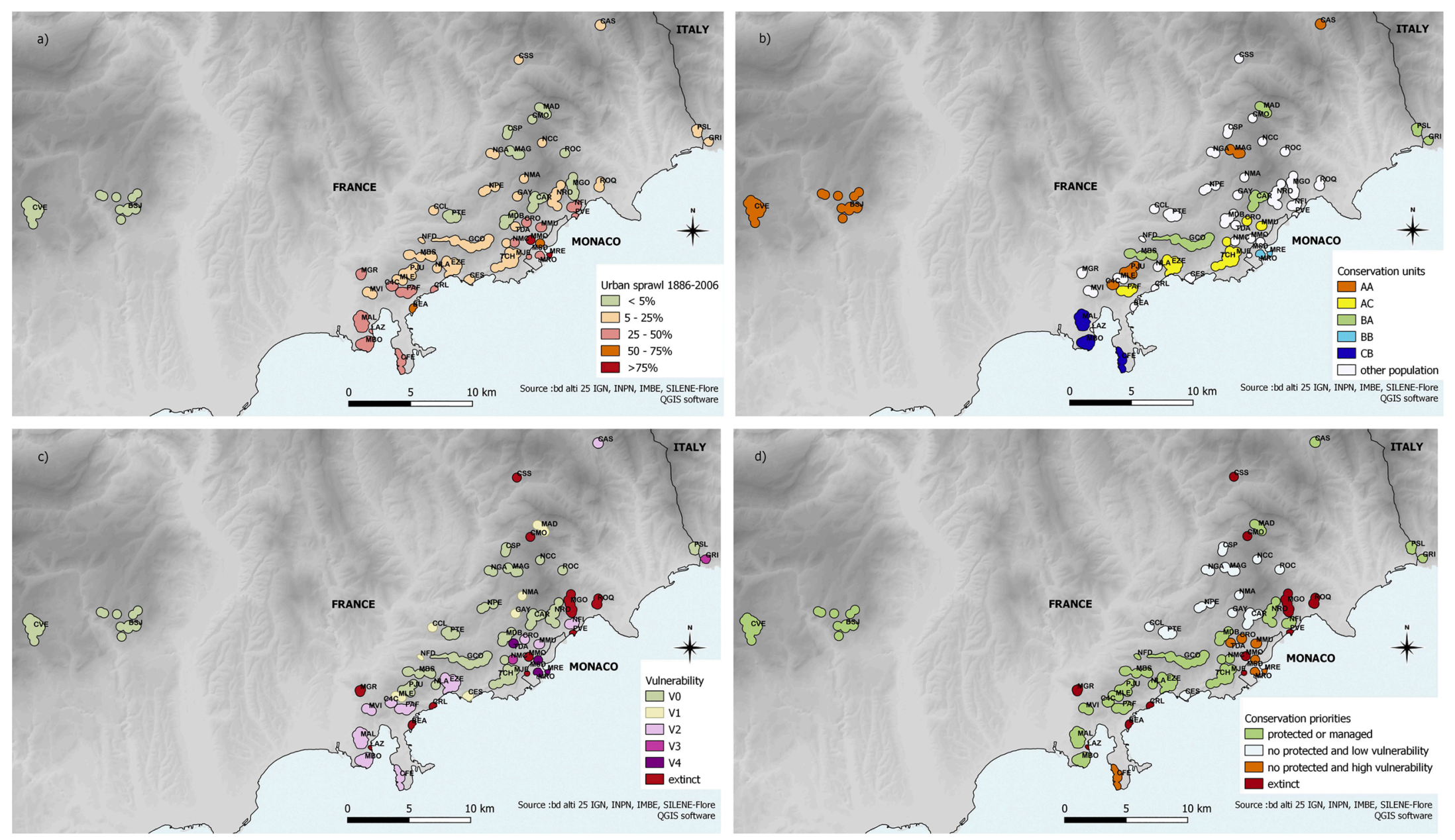

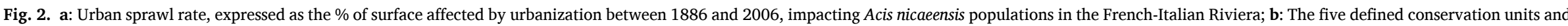

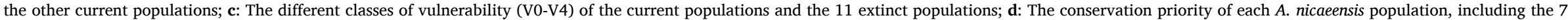
populations in orange proposed as Plant-Micro-Reserves (PMRs). 
Table 1

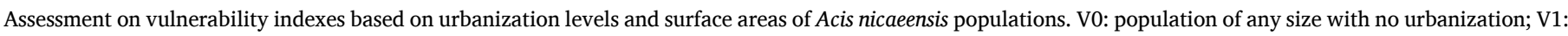

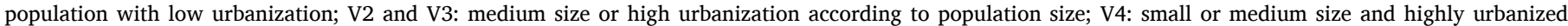
population.

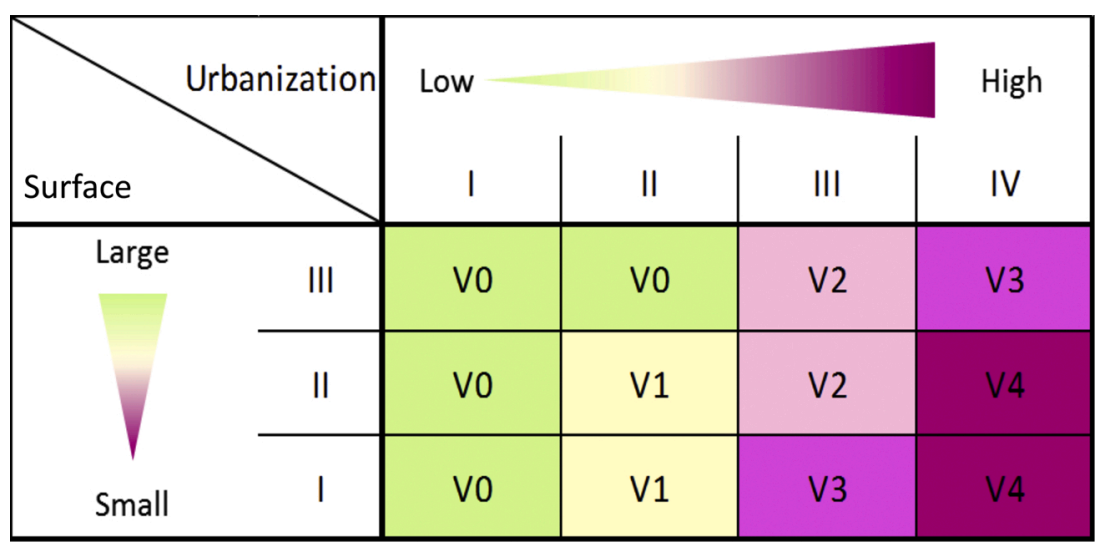

\section{Results}

\subsection{Influence of urban sprawl on the persistence of Acis nicaeensis populations}

The distribution of urbanization in the French-Italian Riviera around the populations of $A$. nicaeensis presents a very distinctive gradient, from very high urbanization ( $>75 \%$ ) near the coast (even near $100 \%$ for MRO population in Monaco) to near absence (e.g. CMO) or low urbanization level $(<25 \%)$ for most of the populations located in the upper altitudinal range (Fig. 2a). The percentage of urbanization was already high in 1866 near the coast (more than $25 \%$, Fig. A1) and higher in 2006 (more than $50 \%$, Fig. A2). The urban sprawl is still highly active on the coast, as represented by the high value of urbanization increase (Fig. A3), and $70 \%$ of the A. nicaeensis population areas suffer from this alteration of natural habitat. A low urbanization level characterizes some isolated populations (e.g. CVE, BSJ or PSL) in the far east and west of the Snowflake's distribution (Fig. 2a). Low urbanization between 1866 and 2006 is observed for the central inland populations (e.g. CAR, GCO, EZE).

Among the 53 known populations occurring at the beginning of the XIXth century, eleven cannot be found nowadays and are considered extinct, i.e. $20 \%$ of all populations (Table A2). There is a very significant correlation between the disappearance of these populations and the urban sprawl. The statistical analysis shows that the median value for urban sprawl is significantly higher for extinct populations (Table A4) and the permutation test confirmed this difference $(\mathrm{p}<5 \%)$. Among the extinct populations, three of them (BEA, MJE and MMO) were impacted by a very high level of urban sprawl (Table A2); three populations (LAZ, PVE and ROQ) were subjected to medium or low levels of urban sprawl between 1866 and 2006 but a high level of urbanization already in 1866, and their last mentions occurred before the beginning of the XXth century; in contrast, two populations (CMO and MGO) are currently subject to a low urbanization level and their disappearance in the 2000s is due to site layout for recreation or outdoor activities. The median urban sprawl rate of the most vulnerable populations (V4) is close to those of already extinct populations (Table A4).

\subsection{Vulnerability of Acis nicaeensis populations}

The majority of A. nicaeensis populations occur in the center of the distribution, whereas few have a high geographical isolation (e.g. CVE and CAS). $45 \%$ of the inventoried populations (i.e. $n=14$,) present less than one hundred individuals and are mainly situated in the south-west of the area (e.g. MAL or MVI). The vulnerability of populations ranges according to the urban pressure and the superficies of each population (Table A1). The most vulnerable ones (classes V2, V3, V4) are found especially along the coast and in the eastern part of the range (Fig. 2c).

The less common conservation units ( $\mathrm{CB}$ and $\mathrm{BB}$ ) are assigned to the vulnerable classes V2 and V4. We must underline the lack of genetic information for two of the most vulnerable (V4 class) populations (MSD and TDA). Populations included in the conservation units AA, AC and $\mathrm{BA}$, are less vulnerable, belonging to V0 class in majority and never reaching the V 3 class.

\subsection{Current protected areas and identification of gaps for a PMR network}

From the 42 current populations of the Snowflake, 16 are included in the global network of protected areas (categories I to IV sensu IUCN) (Fig. A2a) and 24 are partially or totally included in the Natura 2000 network (Fig. A2b). If we consider the spatial congruence of the two networks, 21 populations are more or less protected or managed whereas 13 populations with low vulnerability are located outside of these two networks and, more worryingly, 7 populations with high vulnerability $(\approx 20 \%)$ are not included into a protected area (Fig. 2 d). The latter concerns four populations with high vulnerability and ecoevolutionary originality: the three current populations of the Principality of Monaco (MRO, MRE: BB unit, MSD), and one of the three populations of the $\mathrm{CB}$ unit (CFE). It also concerns also three populations (TDA, CRO, MMU) of the south-eastern part of the range. These seven populations have priority to be included into a PMR network.

\section{Discussion}

\subsection{Urban sprawl as the main threat to Acis nicaeensis populations}

During the last decades the Mediterranean Basin underwent a dramatic increase of urban expansion with a rate of $17 \%$ between 1990 and 2000 (Underwood et al., 2009). In the Mediterranean French region, a land-use change model predicts that $35 \%$ of the sites of high biodiversity interest can potentially be impacted by urbanization over a 20 year period (Vimal et al., 2012). The complex process of urban sprawl (Egidi et al., 2020) represents the main threat for the biodiversity and for the persistence of Mediterranean rare species including narrow endemic plants that often possess distinct conservation units (Médail \& Baumel, 2018). However, very few studies have so far quantified this phenomenon for conservation planning (e.g. Doxa et al., 2017).

Since the last 150 years, the magnitude of the urbanization increase 
is severe for $70 \%$ of the A. nicaeensis populations, and this urban extension is mainly observed along the coast, i.e. along the FrenchItalian Riviera (Médail and Diadema, 2006; Pouget et al., 2017). The extinction of eleven populations has been attested by herbaria records but this is a minimum value since several populations unrecorded in the past may have disappeared (cryptic extinction). Comparisons of land use maps of 1886 and 2006 shown that urban sprawl was significantly higher for extinct populations than for current ones. There is no doubt as to the cause of the disappearance of certain populations (MMO: near Monaco and BEA: Beaulieu-sur-Mer) that are currently in the heart of a massive urban area and for which a complete habitat destruction has been attested. For the others, we found a high and significant correlation between urbanization level and disappearance, especially for LAZ (Lazaret) and ROQ (Roquebrune-Cap-Martin).

Thus our study shows with confidence that urbanization caused the disappearance of most of the extinct $A$. nicaeensis populations. Moreover, our analyses indicate that some situated along the coast (e.g. MRO, MRE, MSD: Monaco or TDA: La Turbie, "Trophée des Alpes") are characterized today by the same level of urbanization and urban sprawl than those characterizing extinct populations. As indicated above, a large part of these populations, embedded in a strong urban environment, have less than one hundred individuals, well below short and long term persistence thresholds (Frankham et al., 2014). So we estimate that there is a high probability of extinction in the short-term due to their very low size and the deleterious effects of urbanization. The extinction of a population is an irreplaceable loss for genetic and ecological attributes, notably in narrow endemic plants with highly diverse genetic structures induced by heterogeneous environments and various historical biogeography as in the Mediterranean Basin hotspot (e.g. Médail \& Baumel, 2018; Thompson, 2020).

\subsection{Integration of conservation units and vulnerability to discriminate PMRs}

The use of conservation units is a relevant tool - still too neglected to better assess the originality of the populations of a species. It relies on the neutral and adaptive components of genetic variation at an intraspecific level (Fraser \& Bernatchez, 2002) and includes the ecological characterization of each considered population (Crandall et al., 2000). For A. nicaeensis, the presence of significant variations at the intraspecific level brings to light the imperative need for a more precise conservation policy. Five conservation units were delineated based on genetic and ecological data (Pouget et al., 2017). Two units present unique evolutionary and ecological properties: the very few populations that compose the CB unit (Nice and St-Jean-Cap-Ferrat) and especially the one of the Principality de Monaco (BB unit) (Fig. 2b).

Once conservation units have been designated, it is necessary to assess the population's vulnerability. We have considered the degree of urbanization affecting both $A$. nicaeensis population and its surface area (Fig. 2a). Among the five conservation units, two (CB and $\mathrm{BB}$ ) are in imminent danger because of their restricted range, the few populations they contain and the low number of individuals per population. These two units are threatened by a very high level of urbanization (more than $75 \%$ ), but also a high competition pressure induced by exotic plants. Because of its location in the outskirt of two big cities (Nice and Monaco), certain populations (e.g. CRO, MMU) of the AC unit are very vulnerable and a regular monitoring is necessary. But urbanization is not the only risk. In the northern part of the distribution, one population is already extinct at Peille (CSS: Chapelle Saint Siméon) probably because of the collapse of traditional agro-pastoral land-uses (Diadema et al., 2007b), and so are two others (CMO and MGO) due to the recent development of recreation activities for the public.

The positive correlation between the significant originality and the high vulnerability of V3 and V4 population groups deserves to be considered in a conservation plan. So it's important to examine the relevance of the current conservation network for the Nice Snowflake in
France, Italy and the Principality of Monaco. Among the 42 current populations, 21 are more or less protected or managed but at least 7 populations with high vulnerability are not protected to date (Fig. 2d). The Natura 2000 protection network represents an important tool for the conservation of the habitats of the Nice Snowflake since it integrates $57 \%$ of the populations. The spatial congruence is also poor with the global protection network (i.e. nature reserve, national park...) and real major gaps appear, mainly for the most coastal populations (Fig. 2d). The areas where the populations of the two highly threatened conservation units occur (CB and $\mathrm{BB}$ ) are not included in a high level protection area sensu IUCN (Dudley, 2008). The conservation unit BB presents the most vulnerable populations (V4), including the three current populations of Monaco (MRO, MRE and MSD). Due to its very small range size and the strong urbanization of the Principality of Monaco - one of the highest human densities of the world -, the BB unit is the most at risk of extinction and if nothing is done, these populations are likely to go extinct in the near future.

Remnants of intact vegetation within highly urbanized landscapes can still retain endemic or rare species (Aronson et al., 2014). This is the case for the Principality of Monaco, both for endemic plants such as Limonium cordatum (L.) Mill. or Campanula rotundifolia L. subsp. macrorhiza (DC.) Bonnier \& Layens (Médail et al., 2007) and invertebrates such as the Coleoptera Otiorhynchus monoecirupis Lemaire et al. present in only one known locality on the Rocher de Monaco (Lemaire et al., 2012). The designation of PMRs in this small country which does not yet have a protected terrestrial network would be thus a clear priority. It would also be important to define a PMR for the population of the $\mathrm{CB}$ unit localized at St-Jean-Cap-Ferrat (CFE), and for some populations of the south-eastern part of the distribution (e.g. CRO, MMU, TDA) even if their assignment to a specific conservation unit could not be carried out to date. Land owners and stakeholders analysis is now ongoing to best develop a land acquisition strategy or a regular management of the PMRs.

\section{Conclusions}

The present approach provides a more precise and operational framework for site selection of PMRs (Laguna \& Deltoro, 2013). We demonstrate the relevance of developing a cross-analysis for threatened species in highly urbanized and heterogeneous landscapes, including (i) the clear estimate of population vulnerability, (ii) the contribution of each population to the evolutionary potential of the species by designating conservation units, and (iii) the gap analysis of the current protection status for each site. This approach allows a good selection of the priority conservation issues at the species scale.

This study shows the clear impacts of ancient, strong and ongoing urbanization on the populations of a narrow endemic plant, Acis nicaeensis, in the French-Italian Riviera. Despite its status as a protected species at European and national levels, this Snowflake is still very threatened and its future remains uncertain. The conservation status for A. nicaeensis according to the standardized evaluation of the European Union is thus "unfavorable inadequate (U1)" with a tendency towards a deterioration of the state of conservation of the species between the two reports (2013 vs. 2019). Our gap analysis shows that two conservation units are in imminent danger and seven populations with high vulnerability are not protected to date.

The application of the PMRs to these patchy and heterogeneous Mediterranean landscapes is very appropriate, especially to improve the conservation status of the Snowflake in the Principality of Monaco. That country is not concerned by the European Directive 92/43/EEC on the conservation of nature and of wild fauna and flora and there is currently no legal protection status there for this species. The creation of plant microreserves would be probably the best solution to preserve the last remnants of semi-natural habitats where the Snowflake persists and to get a real conservation status for this emblematic plant. 


\section{Declaration of Competing Interest}

The authors declare that there is no conflict of interest.

\section{Acknowledgments}

Field and molecular works were partly funded by the Prince's Government of the Principauté de Monaco, Department of the Environment (project $n^{\circ}$ 389.2018.14: Plan local d'actions pour la nivéole de Nice-Acis nicaeensis, 2018-2020), the Prince Albert II of Monaco Foundation (project MONACOBIODIV) and the DREAL-PACA. This research was part of the PhD thesis of Marine Pouget supported by the Région Sud / Provence-Alpes-Côte d'Azur (Bourse doctorale régionale 2011-2014) and performed at Aix-Marseille University / IMBE. Molecular analyses benefited from equipment and services from the molecular biology facility (SCBM) at IMBE. The current protected area network and the identification of conservation gaps by GIS were performed by Guilhem De Barros (Mediterranean National Botanical Conservatory of Porquerolles). We thank Julien Baret (BIODIV) and Jérôme Volant (ECOMED) for their contribution in the census of the populations, and Adeline Almero, Julie Grondin and Camille Laval for their contribution to this work.

\section{Appendix A. Supplementary data}

Supplementary material related to this article can be found, in the online version, at doi:https://doi.org/10.1016/j.jnc.2021.125980.

\section{References}

Abdel Samad, F., Médail, F., Baumel, A., Siljak-Yakovlev, S., Roukoz, A., Tohmé, G. M. et al. (2021). New insights on the conservation status of the endangered coasta endemic plant Astragalus berytheus (Fabaceae) in Lebanon. Oryx, 55. https://doi.org/ 10.1017/S0030605320000149.

Aronson, M.F.J., La Sorte, F.A., Nilon, C.H., Katti, M., Goddard, M.A., Lepczyk, C.A., et al. (2014). A global analysis of the impacts of urbanization on bird and plant diversity reveals key anthropogenic drivers. Proc. R. Soc. B, 281. 20133330. https:// dx.doi.org/10.1098/rspb.2013.3330.

Baumel, A., Médail, F., Juin, M., Paquier, T., Clares, M., Laffargue, P., et al. (2020). Population genetic structure and management perspectives for Armeria belgenciensis, a narrow endemic plant from Provence (France). Plant Ecology and Evolution, 153, 219-228. https://doi.org/10.5091/plecevo.2020.1702.

Blondel, J., \& Médail, F. (2009). Biodiversity and conservation. In J. C. Woodward (Ed.), The physical geography of the Mediterranean (pp. 615-650). Oxford: Oxford University Press.

Christodoulou, C. S., Griffiths, G. H., \& Vogiatzakis, I. N. (2018). Using threatened plant species to identify conservation gaps and opportunities on the island of Cyprus. Biodiversity and Conservation, 27, 2837-2858. https://doi.org/10.1007/s10531-0181572-4.

Crandall, K. A., Bininda-Emonds, O. R. P., Mace, G. M., \& Wayne, R. K. (2000). Considering evolutionary processes in conservation biology. Trends in Ecology \& Evolution, 15, 290-295. https://doi.org/10.1016/s0169-5347(00)01876-0.

Cuttelod, A., García, N., Malak, D. A., \& Temple, H. (2008). The Mediterranean: A biodiversity hotspot under threat. In J.-C. Vié, C. Hilton-Taylor, \& S. N. Stuart (Eds.), The 2008 review of the IUCN Red list of threatened species. Gland, Switzerland: IUCN.

DeFries, R., Hansen, A., Turner, B. L., Reid, R., \& Liu, J. (2007). Land use change around protected areas: management to balance human needs and ecological function. Ecological Applications, 17, 1031-1038. https://www.ncbi.nlm.nih.gov/pubmed $/ 17555216$

Diadema, K. (2006). Apport de la phylogéographie, de la dynamique et de la structure des populations pour la conservation des végétaux endémiques méditerranéens. PhD Thesis (p. 238 p). Marseille: Université Paul Cézanne Aix-Marseille.

Diadema, K., Médail, F., \& Bretagnolle, F. (2007a). Fire as a control agent of demographic structure and plant performance of a rare Mediterranean endemic geophyte. Comptes Rendus Biologies, 330, 691-700. https://doi.org/10.1016/j. crvi.2007.06.003.

Diadema, K., Médail, F., Castagné, H., Affre, L., Roux, J.-P., \& Bretagnolle, F. (2007b). Écologie, distribution et morphologie comparées des nivéoles de Nice (Acis nicaeensis) et de Fabre (Acis fabrei), Alliaceae endémiques des Alpes maritimes et de la Nesque (Vaucluse). Acta Botanica Gallica, 154, 619-634. https://doi.org/10.1080/ 12538078.2007 .10516083$.

Doxa, A., Albert, C. H., Leriche, A., \& Saatkamp, A. (2017). Prioritizing conservation areas for coastal plant diversity under increasing urbanization. Journal of Environmental Management, 201, 425-434. https://doi.org/10.1016/j. jenvman.2017.06.021.

Dudley, N. (2008). Guidelines for applying protected area management categories. Gland, Switzerland: IUCN.
Egidi, G., Cividino, S., Vinci, S., Sateriano, A., \& Salvia, R. (2020). Towards local forms of sprawl: A brief reflection on Mediterranean urbanization. Sustainability, 12, 582. https://doi.org/10.3390/su12020582.

Frankham, R., Bradshaw, C. J., \& Brook, B. W. (2014). Genetics in conservation management: Revised recommendations for the 50/500 rules, Red List criteria and population viability analyses. Biological Conservation, 170, 56-63. https://doi.org/ 10.1016/j.biocon.2013.12.036.

Fraser, D. J., \& Bernatchez, L. (2002). Adaptive evolutionary conservation: Towards a unified concept for defining conservation units. Molecular Ecology, 10, 2741-2752. https://doi.org/10.1046/j.0962-1083.2001.01411.x.

García-Nieto, A. P., Geijzendorffer, I., Baró, F., Roche, P., Bondeau, A., \& Cramer, W. (2018). Impacts of urbanization around Mediterranean cities: Changes in ecosystem service supply. Ecological Indicators, 91, 589-606. https://doi.org/10.1016/j. ecolind.2018.03.082.

Grimm, N. B., Faeth, S. H., Golubiewski, N. E., Redman, C. L., Wu, J., Bai, X., et al. (2008). Global change and the ecology of cities. Science, 319, 756-760. https://doi. org/10.1126/science.1150195.

Hahs, A. K., McDonnell, M. J., McCarthy, M. A., Vesk, P. A., Corlett, R. T., Norton, B. A., et al. (2009). A global synthesis of plant extinction rates in urban areas. Ecology Letters, 12, 1165-1173. https://doi.org/10.1111/j.1461-0248.2009.01372.x.

Hoban, S., Bruford, M., Jackson, J. D. U., Lopes-Fernandes, M., Heuertz, M., Hohenlohe, P. A., et al. (2020). Genetic diversity targets and indicators in the CBD post-2020 global biodiversity framework must be improved. Biological Conservation, 248, Article 108654. https://doi.org/10.1016/j.biocon.2020.108654.

Hoekstra, J. M., Boucher, T. M., Ricketts, T. H., \& Roberts, C. (2005). Confronting a biome crisis: Global disparities of habitat loss and protection. Ecology Letters, 8 , 23-29. https://doi.org/10.1111/j.1461-0248.2004.00686.x.

Kadis, C., Thanos, C. A., \& Laguna Lumbreras, E. (Eds.). (2013). Plant micro-reserves: From theory to practice. Experiences gained From EU LIFE and other related projects. Athens: Utopia Publishing.

Laguna, E., \& Deltoro, V. I. (2013). PMR site selection and boundaries procedures. In C. Kadis, C. A. Thanos, \& E. Laguna Lumbreras (Eds.), Plant micro-reserves: From theory to practice. Experiences gained From EU LIFE and other related projects (pp. 117-126). Athens: Utopia Publishing.

Laguna, E., Deltoro, V. I., Pèrez-Botella, J., Pèrez-Rovira, P., Serra, L., Olivares, A., et al. (2004). The role of small reserves in plant conservation in a region of high diversity in eastern Spain. Biological Conservation, 119, 421-426. https://doi.org/10.1016/j. biocon.2004.01.001.

Laguna, E., Fosa, S., Jiménez, J., \& Volis, S. (2016). Role of micro-reserves in conservation of endemic, rare and endangered plants of the Valencian region (Eastern Spain). Israel Journal of Plant Sciences, 63, 320-332. https://doi.org/ 10.1080/07929978.2016.1256131.

Le Roux, J., Hui, C., Castillo, M., Iriondo, J. M., Keet, J.-H., Khapugin, A., et al. (2019). Recent anthropogenic plant extinctions differ in biodiversity hotspots and coldspots. Current Biology, 29, 2912-2918. https://doi.org/10.1016/j.cub.2019.07.063.

Lefebvre, T., \& Moncorps, S. (2010). Les espaces protégés français : Une pluralité d'outils au service de la conservation de la biodiversité. Paris: Comité français pour l'UICN.

Lemaire, J.-M., Ponel, P., \& Alziar, G. (2012). Les Curculionides cavernicoles de la région niçoise, France. III. Description d'Otiorhynchus (Lixorrhynchus) monoecirupis $\mathrm{n}$. sp. de Monaco (Coleoptera, Curculionidae, entiminae). Bulletin de la Société entomologique de France, 117, 283-287.

Lhotte, A., Affre, L., \& Saatkamp, A. (2014). Are there contrasted impacts of urbanization and land uses on population persistence? The case of Teucrium pseudochamaepitys, an endangered species in Southern France. Flora, 209, 484-490. https://doi.org/ 10.1016/j.flora.2014.05.002.

Mcdonald, R. I., Kareiva, P., \& Forman, R. T. T. (2008). The implications of current and future urbanization for global protected areas and biodiversity conservation. Biological Conservation, 141, 1695-1703. https://doi.org/10.1016/j. biocon. 2008.04.025.

McKinney, M. L. (2002). Urbanization, biodiversity, and conservation. BioScience, 52, 883-890. https://doi.org/10.1641/0006-3568(2002)052[0883:UBAC]2.0.CO;2.

Médail, F., \& Baumel, A. (2018). Using phylogeography to define conservation priorities: The case of narrow endemic plants in the Mediterranean Basin hotspot. Biological Conservation, 224, 258-266. https://doi.org/10.1016/j.biocon.2018.05.028.

Médail, F., \& Diadema, K. (2006). Biodiversité végétale méditerranéenne et anthropisation : Approches macro et micro-régionales. Annales de Géographie, special issue « Les territoires de la biodiversité », 651, 618-649. https://doi.org/10.3917/ ag.651.0618.

Médail, F., \& Quézel, P. (1997). Hot-Spots analysis for conservation of plant biodiversity in the Mediterranean Basin. Annals of the Missouri Botanical Garden, 84, 112-127. https://doi.org/10.2307/2399957.

Médail, F., Diadema, K., \& Salanon, R. (2007). Inventaire de la flore terrestre spontanée de la Principauté de Monaco. Le Journal de botanique de la Société botanique de France, 39, 37-55.

Orsenigo, S., Montagnani, C., Fenu, G., Gargano, D., Peruzzi, L., Abeli, T., et al. (2018). Red Listing plants under full national responsibility: Extinction risk and threats in the vascular flora endemic to Italy. Biological Conservation, 224, 213-222. https:// doi.org/10.1016/j.biocon.2018.05.030.

Pouget, M., Baumel, A., Diadema, K., \& Médail, F. (2017). Conservation unit allows assessing vulnerability and setting conservation priorities for a Mediterranean endemic plant within the context of extreme urbanization. Biodiversity and Conservation, 26, 293-307. https://doi.org/10.1007/s10531-016-1242-3.

QGIS Development Team. (2020). QGIS geographic information system. Open source geospatial foundation project. Retrieved from http://qgis.osgeo.org.

R Development Core Team. (2020). R: A language and environment for statistical computing. Vienna: R Foundation for Statistical Computing. 
Sulis, E., Bacchetta, G., Cogoni, D., Gargano, D., \& Fenu, G. (2020). Assessing the global conservation status of the rock rose Helianthemum caput-felis. Oryx, 54, 197-205.

https://doi.org/10.1017/S0030605318001424.

Thompson, J. D. (2020). Plant evolution in the Mediterranean. Insights for conservation (second edition). Oxford: Oxford Univ. Press.

UICN France, FCBN, AFB, \& MNHN. (2018). La Liste rouge des espèces menacées en FranceChapitre Flore vasculaire de France métropolitaine. Paris, $31 \mathrm{p}$.

Underwood, E. C., Viers, J. H., Klausmeyer, K. R., Cox, R. L., \& Shaw, M. R. (2009).

Threats and biodiversity in the mediterranean biome. Diversity \& Distributions, 15 ,

188-197. https://doi.org/10.1111/j.1472-4642.2008.00518.x.

UNEP/MAP, \& Plan Bleu. (2020). State of the environment and development in the Mediterranean. Nairobi: United Nations Environment Programme.
United Nations. (2018). World economic situation and prospects.

Vimal, R., Geniaux, G., Pluvinet, P., Napoleone, C., \& Lepart, J. (2012). Detecting threatened biodiversity by urbanization at regional and local scales using an urban sprawl simulation approach: Application on the French Mediterranean region. Landscape and Urban Plannning, 104, 343-355. https://doi.org/10.1016/j. landurbplan.2011.11.003.

Wenzel, A., Grass, I., Belavadi, V. V., \& Tscharntke, T. (2020). How urbanization is driving pollinator diversity and pollination - A systematic review. Biological Conservation, 241. https://doi.org/10.1016/j.biocon.2019.108321.

With, K. A. (2002). The landscape ecology of invasive species. Conservation Biology, 16, 1192-1203. https://doi.org/10.1046/j.1523-1739.2002.01064.x. 